\title{
Synchronous vs. Asynchronous vs. Blended Remote Delivery of Introduction to Biomechanics Course
}

\author{
Nicole L. Ramo (1), ${ }^{1}$ Mei'Ai Lin, ${ }^{2}$ Eric S. Hald, ${ }^{2}$ and Aileen Huang-SaAd ${ }^{1}$ \\ ${ }^{1}$ Biomedical Engineering, University of Michigan, Ann Arbor, MI, USA; and ${ }^{2}$ Biomedical Engineering, Shantou University, \\ Shantou, Guangdong, China
}

(Received 24 June 2020; accepted 21 July 2020; published online 18 August 2020).

\section{CHALLENGE STATEMENT}

The faculty of the Department of Biomedical Engineering at Shantou University was intentionally developed to include instructors with international teaching or training experience. Accordingly, six of the ten full-time faculty are non-Chinese nationals with varying international citizenship. When COVID-19 necessitated the transition to remote instruction between the fall and spring semesters, these international faculty members left mainland China for their respective home countries while all students relocated to their family homes in mainland China. As a result, students and instructors were faced with time zone disparities of 2-14 $\mathrm{h}$ and home learning environments that were often embedded in shared living spaces of an apartment.

To address these challenges, instructors needed to establish an appropriate balance between synchronous and asynchronous teaching. This article systematically describes commonly used evidence-based teaching practices and how they were implemented in three versions of remote instruction (each with a different balance of synchronous and asynchronous teaching). The course context was a 2nd-year lecture-based introduction to biomechanics course team-taught by two faculty members, one based in China and one based in the United States (US).

Address correspondence to Nicole L. Ramo, Biomedical Engineering, University of Michigan, Ann Arbor, MI, USA. Electronic mail:nramo@umich.edu

\section{NOVEL INITIATIVE}

The biomechanics course was divided into three, subject-specific sections: statics, dynamics, and mechanics of materials. While all sections leveraged the same instructional technologies and software tools, each section had a different ratio of synchronous to asynchronous components based on instructor preference and availability. First, the specific technologies and tools utilized will be discussed and then a comparison between the delivery approaches of each section will be presented.

Specific Remote Delivery Technologies and Tools

General Tools/Pedagogical Techniques Used for Both Delivery Methods

Handout/Worksheet for Each Lecture Providing guided notes (i.e., "skeleton notes") to students can improve attention and academic performance, perhaps by allowing students time to process and synthesize information as opposed to superficially writing every word presented during a lecture. ${ }^{1,4}$ Accordingly, guided notes for each synchronous and asynchronous lecture were made available as downloadable handouts (examples of two such handouts are given as supplemental material). Each handout contained highlighted blanks which the students were expected to complete during the lecture. Students were also encouraged to add their own notes and any figures or drawings that would help them understand or remember the content. 
No answer key was provided for the handouts; instead, students could add any unresolved questions to their weekly discussion posts described below.

Clear and Observable Learning Objectives for Each Lecture In general, it is important to make expectations explicit so students can engage in more selfmonitored learning and self-directed review $^{3}$; this is even more critical in remote learning settings where the typical peer or instructor support structures are less readily available. ${ }^{10}$ Therefore, every lecture and handout started with 3-5 learning objectives. These were clear statements describing what students should be able to do based on the content presented in that lecture.

\section{Asynchronous Components \{Platform or Tool\}}

Narrated mp4 Lecture Videos \{Microsoft PowerPoint $\}$ The method of presenting new information using PowerPoint slides was familiar to both the instructors and students; it also allowed most of the slides used for in-person instruction to be used for remote teaching. Most recent versions of PowerPoint allow presentations to be exported as mp4 videos including narrations, slide timings and animations, virtual laser pointer, and "ink" markings (video from a webcam is also available for Microsoft 365 subscribers). ${ }^{7}$ The US-based faculty member narrated each slide, using the built-in presentation tools (e.g., highlight, laser pointer, etc.) the same way they would for in-person lectures. As the recordings are saved for individual slides, any slide could be re-recorded if the initial narration was unclear or unfocused. Student engagement exercises were incorporated every 10-20 min during playback. These activities asked the students to pause the video to either read the next handout section, complete the previous handout section, or attempt to solve a problem (the solution to which is given as the next part of the video).

Weekly Discussion Posts \{Office 365 (or Google Slides)\} Discussion forums are the most common means of whole-class asynchronous communication and interaction; they not only provide flexibility and opportunities for refection, but can also create a sense of community in online courses through sustained interaction and feedback. ${ }^{9,10,12,13}$ Posting PowerPoint slides from every lecture (asynchronous or synchronous) to the course Microsoft SharePoint website allowed students to open and collaboratively edit the file online using PowerPoint for Office 365 . Before the end of every week, students were required to post two comments on the lecture slides for that week. These comments could be questions, answers to peers' questions, links to additional learning resources, or relevant examples, comments, or reflections (Fig. 1). At the end of the week, the instructor reviewed all of the posts; addressing most through in-line comments while identifying common themes or points of confusion that were addressed in subsequent asynchronous videos or synchronous lectures.

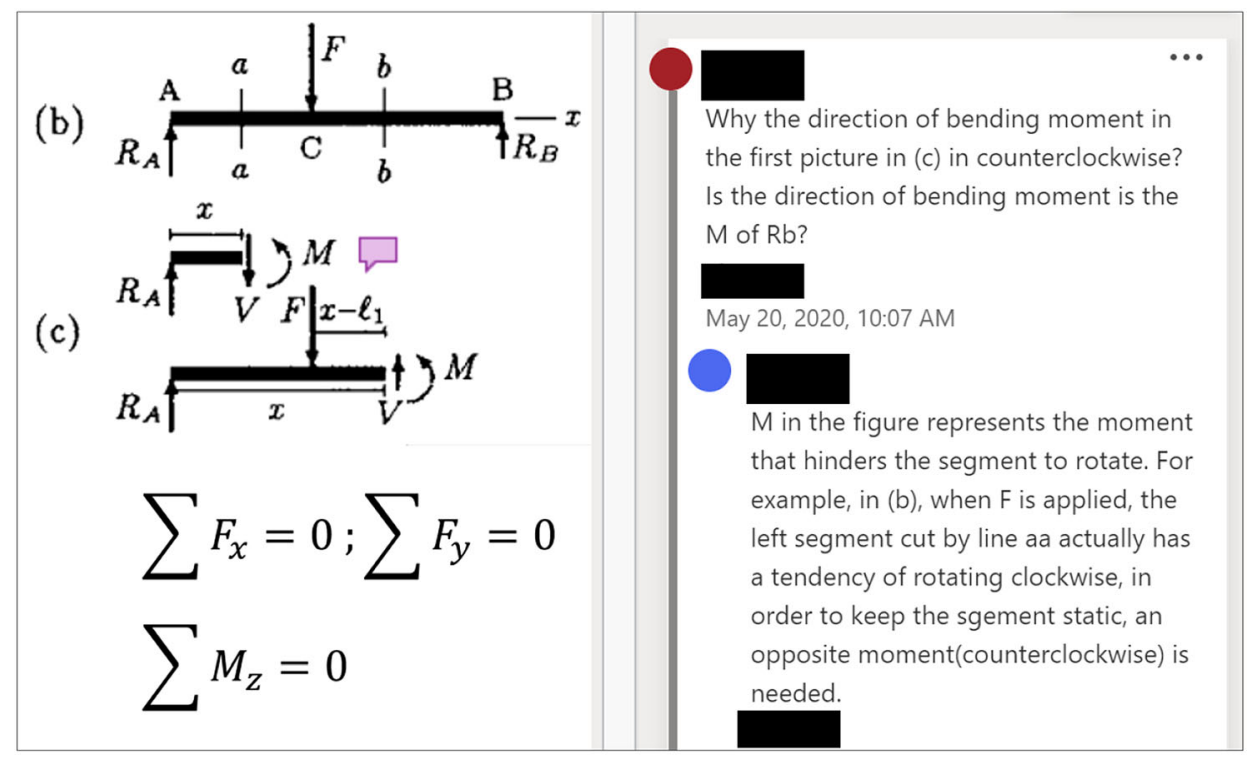

FIGURE 1. Example of peer dialogue in PowerPoint for Microsoft 365. 
Synchronous Components $\{$ Platform or Tool\}

Live Lectures \{Zoom: Screen Share\} Live PowerPointbased lectures were given using the share screen feature in Zoom. The advanced sharing feature "Portion of Screen" 15 was used in conjunction with the PowerPoint presenter view to display the current slide, speaker notes, and next slide to the instructor while displaying only the current slide to students. Student engagement activities were also incorporated during the live lectures where students volunteered or were cold-called to provide their answers. Attendance was mandatory for each of the live lectures. Zoom-created recordings of the live lectures were posted to the course website such that students could download and review the lecture at a later time.

Discussion of Academic Journal Article \{Zoom: breakout rooms and screen share The instructors felt it was important to introduce students to current research efforts in the field of biomedical engineering to not only increase exposure and interest, but also to demonstrate the applicability and value of course content in addressing on-going questions or problems in the field - a characteristic of authentic learning. ${ }^{11}$ Therefore, four academic journal articles, each based on a different aspect of biomechanics, were assigned for live discussion. Associated discussion questions were posted approximately one week before each scheduled discussion with pre-class answers to these questions graded for completion. During the live Zoom discussion, the instructor provided an overview of the article as well as the answers to the easier discussion questions (ones that could be found directly in the article text). Then, students were separated into groups of four or five using the breakout room feature of Zoom ${ }^{14}$ with each group assigned one of the remaining questions (ones that required external research, synthesis of article information, or drawing connections to specific lecture content). The students spent 15-30 min in their small group to develop a consensus answer, creating one or two slides to explain their answer and nominating a "group captain." The breakout rooms were then closed, and all participants returned to the main meeting where each group shared their screen in turn while the "group captain" presented their answer. The instructors helped guide the discussion by posing follow-up questions and summarizing important points. After discussion, each student updated their pre-class answers and submitted a post-class assignment which was graded for accuracy.

\section{Remote Delivery Approaches}

The first four weeks of the course focused on statics and was delivered by the US-based faculty member in a blended fashion with both synchronous and asynchronous components. Two lecture videos, each totaling approximately $60-90 \mathrm{~min}$ in length (not including pauses for engagement exercises), were posted at the beginning of every week. Students were responsible for watching the videos, completing the associated handouts, and submitting at least two discussion posts by the end of the week. On Fridays, a 30min Zoom lecture was held to address the main points of confusion (as identified in discussion posts).

The second section of the course focused on dynamics and was delivered by the China-based faculty member in a largely synchronous way. Live Zoom lectures, each 100 min long including a 10-min break, were held twice a week. Students were still required to submit two comments on the PowerPoint files; these submitted comments and questions were addressed during the first lecture of the following week.

The final section of the course focused on the mechanics of materials and was delivered by the USbased faculty member in a primarily asynchronous way. The main difference between this section and the initial (blended) approach was the frequency of synchronous class sessions. During the first section of the course, the class met weekly to review the comments and questions submitted as discussion posts. During the final section of the course, the discussion posts were addressed in short, stand-alone review videos; the only synchronous class session of this course section was a journal article discussion.

\section{REFLECTION}

Between the dynamics and mechanics of materials sections of the class, students were asked to complete a survey concerning the online implementation (response rate: $33 / 35$ ). Students responded positively to the guided notes. $76 \%$ of students reported that they consistently used them; $95 \%$ of those students found them somewhat or very helpful to their learning. Consistent with the literature, ${ }^{1,4}$ students indicated that: "I can focus on the class more;" "I can listen to the lecture [more] efficiently;" and "[they] guide me when I am listening to the lecture."

Students were initially resistant to the requirement of discussion posts because it was not clear how it would aid their learning. In a private correspondence to the US-based instructor after three weeks of the course, a class representative stated "in our high schools, most of the students are not encouraged to ask questions; so 
now some of us are confused about the significance." Based on this feedback, the instructor used part of that week's live review session to explicitly discuss the benefit of these posts, both for the instructors and for the students. By the time of the survey, $86 \%$ of respondents reported they understood the purpose of the weekly discussion posts assignment, and $89 \%$ found the assignment somewhat or very helpful for their learning. The accompanying comments from students underscore the reflective and collaborative benefits of asynchronous discussion threads ${ }^{9,13}$ : "[the posts] allow us to think about the knowledge we have learned, which helps deepen the impact;" "helps me test myself and review the content;" "asking my questions and solving others' questions helped me to have a better understanding of what I was learning;" "I learned a lot from the comments of my classmates."

At the time of this submission, the Shantou University semester is still on-going; therefore, data on student perceptions of the largely asynchronous delivery method have yet to be collected. However, in the survey data currently available, students expressed a preference for the blended approach over the largely synchronous approach (Fig. 2). Examining accompanying student survey comments, the accepted benefits of flexibility, convenience, and ability to personalize learning were frequently noted. ${ }^{2,12}$ For example, "I can choose my own time to study;" "the time is flexible;" "narrated videos give me more freedom...if I miss some points, I can pause and watch that part of the video again;" "I can repeat the points which I didn't get and skip the parts I know."

However, the minority of students who expressed a preference for synchronous lectures cited the desire for more direct interaction with their instructor and peers, consistent with the literature on feelings of isolation

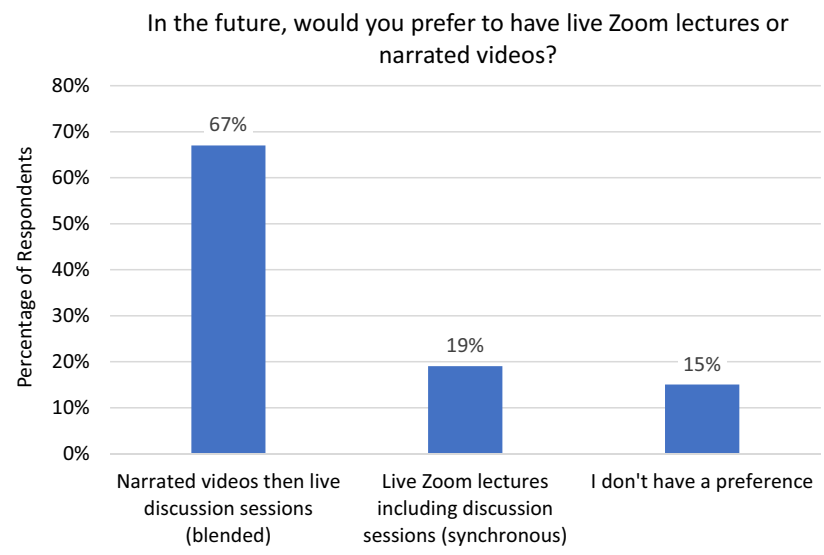

FIGURE 2. Students expressed a strong preference for the blended instruction of the first section of the course compared to the largely synchronous instruction of the middle section of the course. and lack of immediacy that may result from asynchronous instruction., ${ }^{2,9,12}$ One specific comment stated, "I like [the live Zoom lectures] because I have more interactions with teachers and classmates which makes the classes interesting."

\section{Future Remote Offerings}

Although we do not have post-course survey results at this time, the instructors feel that the biggest challenge was facilitating student engagement and interaction, especially during live synchronous lessons. The strong student preference for a blended approach over a synchronous approach could reflect not only a preference for that delivery method, but also an indication that we were not leading effective synchronous lectures (indeed, this feeling was one motivation for trying the primarily asynchronous delivery of the final section of the course). Therefore, in future offerings of lecture-based online courses, the instructors will adopt a blended approach that follows the "flipped-class" model. In a "flipped-class," instructional content is delivered to students asynchronously outside of class (typically through online videos); synchronous in-class time is devoted to discussion, application, and/or collaborative learning. ${ }^{3,8}$

An online flipped-class could look like the following, which describes our plan for future remote offerings of this lecture-based course: At the beginning of every week, a series of shorter (10 min or less), topicspecific, narrated videos will be posted along with a guided note handout. These videos could be edited/ trimmed versions of those created during the spring 2020 semester. The weekly discussion posts assignment will continue, but an auto-graded weekly quiz assignment will be added to the course learning management system. This quiz will help students more directly assess their knowledge based on the week's learning objectives and identify areas of confusion about which to inquire and discuss. The asynchronous narrated videos will include fewer problems for the students to solve independently; instead, those engagement activities will be moved to a weekly synchronous class session. These activities could be done in a "think-pairshare" format ${ }^{3,8}$ with the "pair" being a small group in a Zoom breakout room and the "share" involving screen sharing of solutions with the rest of the class. The common points of confusion identified in the discussion posts will also be addressed during these live sessions, but with more emphasis on soliciting input and explanation from students who submitted comments, questions, or answers. Journal article discussions will continue to be implemented monthly to demonstrate the applicability of course content. 
The authors believe the "flipped-class" model described above leverages the perceived benefits of both synchronous and asynchronous components. It also aligns with many of the practices supported by pedagogical research and recent student surveys ${ }^{5,6}$ including the following:

- "Breaking up [content] into [smaller] pieces.

- Assignments that ask students to express what they have learned and what they still need to learn.

- Frequent quizzes or other assessments.

- Live sessions in which students can ask questions and participate in discussions.

- Meeting in "breakout groups" during a live class.

- Using real-world examples to illustrate course content.

A final advantage of this approach is that it can easily be adapted for in-person classes once both instructors and students are safely back on campus. Across future offerings of the course, quantitative comparison of summative assessment results (e.g., mid-term and final exam scores), as well as qualitative comparison of the depth and sophistication of discussion post threads, will help assess the influence of different modes of delivery on student learning outcomes.

\section{ELECTRONIC SUPPLEMENTARY MATERIAL}

The online version of this article (https://doi.org/10. 1007/s43683-020-00009-w) contains supplementary material, which is available to authorized users.

\section{AUTHOR CONTRIBUTIONS}

Development and teaching of the course was done by NR and ML. Student survey data was collected and reviewed by NR. Teaching support and guidance was provided by $\mathrm{EH}$ and $\mathrm{AH}-\mathrm{S}$. Assistance in connecting to engineering education literature was provided by $\mathrm{AH}-$ S. The first draft of the manuscript was written by NR and all authors commented on previous versions of the manuscript. All authors read and approved the final manuscript.

\section{FUNDING}

No external funding support.

\section{CONFLICT OF INTEREST}

The authors declare that they have no conflict of interest.

\section{ETHICAL APPROVAL}

The data reported in this article are from an anonymous student survey administered in the course of normal education practice. Ethics board review is not required in accordance with the ethical standards of our institution.

\section{REFERENCES}

${ }^{1}$ Austin JL, Lee MG, Thibeault MD, Carr JE, Bailey JS. Effects of guided notes on university students' responding and recall of information. J Behav Educ. 2002;11(4):24354.

${ }^{2}$ Beyth-Marom R, Saporta K, Caspi A. Synchronous vs. asynchronous tutorials: factors affecting students' preferences and choices. J Res Technol Educ. 2005;37(3):245-62. ${ }^{3}$ Felder RM, Brent R. Teaching and learning STEM: a practical guide. San Francisco, CA: Jossey-Bass; 2016.

${ }^{4}$ Konrad M, Joseph LM, Eveleigh E. A meta-analytic review of guided notes. Educ Treat Child. 2009;32(3):421-44.

${ }^{5}$ Lederman D. What worked this spring? Well-designed and -delivered courses. Inside Higher Ed Transform. Teach. Learn. [Online]; 2020. https://www.insidehighered.com/dig ital-learning/article/2020/07/08/what-kept-students-studyi ng-remotely-satisfied-spring-well. Accessed 14 Jul 2020.

${ }^{6}$ Means B, Neisler J. Suddenly online: a national survey of undergraduates during the COVID-19 pandemic. San Mateo, CA: Digital Promise; 2020.

${ }^{7}$ Microsoft Support. Record a slide show with narration and slide timings. Present slide shows [Online]. https://support. microsoft.com/en-us/office/record-a-slide-show-with-narra tion-and-slide-timings-0b9502c6-5f6c-40ae-b1e7-e47d8741 161c. Accessed 6 Jun 2020.

${ }^{8} \mathrm{O}$ 'Flaherty J, Phillips C. The use of flipped classrooms in higher education: a scoping review. Internet High Educ. 2015;25:85-95.

${ }^{9}$ Pavlis-Korres M. The role of the communication tools in the development of the learning group in an online environment. Int J Eng Educ. 2012;28(6):1360-65.

${ }^{10}$ Roddy C, Amiet DL, Chung J, Holt C, Shaw L, McKenzie S, Garivaldis F, Lodge JM, Mundy ME. Applying best practice online learning, teaching, and support to intensive online environments: an integrative review. Front Educ. 2017;2:59.

${ }^{11}$ Rule A. Editorial: the components of authentic learning. J Authentic Learn. 2006;3(1):1-10.

${ }^{12}$ Sunal DW, Sunal CS, Odell MR, Sundberg CA. Researchsupported best practices for developing online learning. J Interact Online Learn. 2003;2(1):1-40.

${ }^{13}$ Watts L. Synchronous and asynchronous communication in distance learning: a review of literature. Q Rev Distance Educ. 2016;17(1):23-32.

${ }^{14}$ Zoom Help Center. Managing breakout rooms. Settings Control [Online]. https://support.zoom.us/hc/en-us/articles /206476313-Managing-breakout-rooms. Accessed 13 Jun 2020. 
${ }^{15}$ Zoom Help Center. Sharing your screen in a meeting. Audio, Video, Shar. [Online]. https://support.zoom.us/hc/e n-us/articles/201362153-Sharing-your-screen-in-a-meeting. Accessed 13 Jun 2020.
Publisher's Note Springer Nature remains neutral with regard to jurisdictional claims in published maps and institutional affiliations. 